Article

\title{
Dry Sliding Wear Behavior of Spark Plasma Sintered Fe-Based Bulk Metallic Glass/Graphite Composites
}

\author{
Xiulin Ji ${ }^{1}$, S. Habib Alavi ${ }^{2}$ and Sandip P. Harimkar ${ }^{2, *}$ \\ 1 College of Mechanical \& Electrical Engineering, Hohai University, Changzhou 213022, China; \\ xiulinji@gmail.com \\ 2 School of Mechanical and Aerospace Engineering, Oklahoma State University, Stillwater, OK 74078, USA; \\ habib.alavi@okstate.edu \\ * Correspondence: sandip.harimkar@okstate.edu; Tel.: +1-405-744-5830
}

Academic Editor: Manoj Gupta

Received: 31 July 2016; Accepted: 29 August 2016; Published: 2 September 2016

\begin{abstract}
Bulk metallic glass (BMG) and BMG-graphite composites were fabricated using spark plasma sintering at the sintering temperature of $575^{\circ} \mathrm{C}$ and holding time of $15 \mathrm{~min}$. The sintered composites exhibited partial crystallization and the presence of distributed porosity and graphite particles. The effect of graphite reinforcement on the tribological properties of the BMG/graphite composites was investigated using dry ball-on-disc sliding wear tests. The reinforcement of graphite resulted in a reduction in both the wear rate and the coefficient of friction as compared to monolithic BMG samples. The wear surfaces of BMG/graphite composites showed regions of localized wear loss due to microcracking and fracture, as was also the case with the regions covered with graphite-rich protective film due to smearing of pulled off graphite particles.
\end{abstract}

Keywords: bulk metallic glass; spark plasma sintering; solid lubrication; graphite; wear; tribology

\section{Introduction}

Bulk amorphous alloys (BAA), also referred to as bulk metallic glasses (BMGs), are emerging as potential materials for a range of applications in structural [1], biomedical [2], microelectromechanical systems (MEMS) [3], and sports equipment engineering [4] due to their excellent mechanical and electrochemical properties. Several compositions of BMGs based on $\mathrm{Fe}-, \mathrm{Zr}_{-}, \mathrm{Cu}-, \mathrm{Mg}-$, $\mathrm{Ti}-$, $\mathrm{Ni}-$, and Pd-based alloy systems have been developed [5]. The amorphous alloys, in the form of coatings, are also being considered in diverse applications [6-8]. In most of these applications of amorphous alloys and their coatings, wear and friction properties are of primary interest or at least an important consideration. The tribological properties of the amorphous alloys have been extensively investigated [9-13]. The wear performance of amorphous alloys and composites is extensively reviewed by Greer et al. [10]. Most of the earlier investigations on the topic were focused on investigating the tribological performance of the amorphous alloys as compared to conventional crystalline materials. The wear performance of the amorphous alloys is heavily influenced by the testing conditions, and several conflicting reports about the general merits of amorphous alloys over crystalline materials exist. In general, the amorphous alloys offer better wear performance in sliding wear conditions, but respond relatively poorly in abrasive and fretting wear conditions as compared to conventional crystalline materials [10].

Several mechanisms that affect the wear performance of the amorphous alloys have been identified. As amorphous alloys lack general ductility, the wear behavior of these materials is characterized by shear banding and microcracking in the contact region $[9,14,15]$. Matthews et al. investigated the dry sliding wear behavior of as-cast and laser remelted $\mathrm{Cu}$-based amorphous alloys and observed formation of shear bands inclined to the sliding direction [15]. It was also observed that, 
as the wear continues, the asperities of the shear bands break down, resulting in accumulation and compaction of micro- and nano-scale debris behind the shear bands. While the amorphous alloys showed a lower coefficient of friction, the wear rates were comparable to the steel specimens [15]. Prakash investigated abrasive two-body wear of $\mathrm{Fe}-, \mathrm{Co}-$, and Ni-based amorphous alloys and reported extensive micro-cutting and micro-cracking of the amorphous alloys [9]. In spite of its higher hardness, the wear performance of Fe-based amorphous alloys was only marginally superior to that of stainless steel. The Ni-based amorphous alloys actually showed higher wear rates than the stainless steel [9]. The wear testing conditions can also cause structural relaxation and partial devitrification of amorphous alloys due to contact stress (mechanical) and frictional heat (thermal) mechanisms $[10,13]$. The crystallization products in amorphous alloys most often embrittle the material [16]. The microcracking at the crystal interfaces and removal of hard particles further deteriorate the wear performance. Oxidation of the contact region and the wear debris has also been frequently observed under dry sliding wear conditions $[13,15]$. Singh et al. investigated the dry sliding wear performance of Fe-based amorphous alloys in sintered (amorphous) and thermally annealed (partially crystalline) conditions. The formation of coarse oxygen-rich debris around predominantly amorphous islands on the wear surface was observed for both amorphous and partially crystalline samples. The partially crystalline samples exhibited relatively superior wear performance to the amorphous samples [13]. The material removal by oxidative wear is also reported for Cu-based amorphous alloys under sliding wear conditions [15]. The formation of hard oxide debris can bring additional abrasive mechanisms of wear into action. All the effects, such as viscous flow, structural relaxation, partial devitrification, and oxidation at the contact region can lead to transitions in wear mechanisms of amorphous alloys and affect wear rates [10,17].

Some efforts have been made to alter the wear behavior of amorphous alloys by introducing second phases in the material using in-situ and ex-situ composite design approaches $[14,18]$. The in-situ amorphous matrix composites can be formed by annealing fully amorphous alloys above the crystallization temperature [19]. The partial devitrification during annealing results in significant hardening in the resultant in-situ composites [13]. Under mild wear testing conditions, the in-situ composites, with higher hardness, exhibit improved wear resistance than the fully amorphous alloys $[13,20]$. However, the wear resistance of amorphous alloys and composites does not always scale up with hardness [10]. The embrittlement of the in-situ composites may reduce the wear resistance under severe wear conditions. The ex-situ amorphous composites are formed by adding a low volume content of second phase, typically ceramic particles, to the amorphous matrix. It has been widely reported that ex-situ amorphous composites show enhancement in their mechanical and tribological properties [21,22]. For example, Yue and Su reported significant improvement in hardness and dry sliding wear resistance with $\mathrm{SiC}$ reinforcement in laser clad $\mathrm{Zr}$-based amorphous alloys [22]. Some recent efforts have been directed towards using graphite reinforcement in amorphous alloys with an aim to improve the tribological properties $[14,18]$. Siegrist et al. reported significant reduction in the coefficient of friction with low volume content graphite reinforcement in cast Zr-based amorphous alloys [14]. Wang et al. also reported wear behavior of laser clad Zr-based amorphous alloys reinforced with graphite [18]. While the fully amorphous structure was not retained in the laser clad surfaces, the addition of graphite reduced the coefficient of friction. The reaction between the constituent phases forming $\mathrm{ZrC}$ was also observed, especially at high graphite content.

Recently, Fe-based amorphous alloys, sometimes referred to as amorphous steels, are emerging as promising materials for structural application because of the combination of higher hardness/strength and excellent corrosion resistance compared to conventional crystalline steels [23]. The Fe-based amorphous alloys with $\mathrm{Y}$ addition also exhibit excellent formability with possibilities to fabricate rod shaped samples with a maximum diameter of up to $12 \mathrm{~mm}$ using casting techniques [24]. The bulk shapes of Fe-based amorphous alloys have also been produced by spark plasma sintering (SPS) using starting amorphous alloy powder [25-27]. The tribological performance is likely to be important for further development of applications of this attractive amorphous alloy system. In this paper, 
wear behavior of Fe-based amorphous alloy (BMG) and its composites with graphite reinforcement (BMG/graphite) is investigated under dry sliding wear conditions. The effect of graphite reinforcement levels on the wear rate and coefficient of friction is systematically investigated, and the results are explained based on microscopic observations of the microstructure and wear tracks.

\section{Materials and Methods}

Amorphous alloy powder of nominal composition $\mathrm{Fe}_{48} \mathrm{Cr}_{15} \mathrm{Mo}_{14} \mathrm{Y}_{2} \mathrm{C}_{15} \mathrm{~B}_{6}$ (particle size: $<25 \mu \mathrm{m}$ ) and graphite powder (particle size: $\sim 45 \mu \mathrm{m}$ ) were used for the processing of BMG/graphite composites. The graphite content in composites was varied from $1 \mathrm{wt} \%$ to $4 \mathrm{wt} \%$. For comparison, monolithic BMG specimens ( 0 wt \% graphite) were also processed. For the processing of BMG/graphite composites, the composite powder mixture was prepared by dry mixing the amorphous alloy powder and the graphite powder in desired composition, followed by planetary ball milling at $200 \mathrm{rpm}$ with a ball to powder weight ratio of 10:1. High performance stainless steel vials and tungsten carbide balls were used for milling. The ball milling consisted of a total of 20 cycles of 1 min each with a 14 min pause between the cycles. The composite mixtures were sintered in a commercial SPS machine (Thermal Technology LLC, Santa Rosa, CA, USA) using graphite dies and punches to produce disc-shaped specimens of $15 \mathrm{~mm}$ diameter and 2-3 mm height. The sintering was performed at $575^{\circ} \mathrm{C}$, attained at a heating rate of $100{ }^{\circ} \mathrm{C} / \mathrm{min}$, with uniaxial pressure of $70 \mathrm{MPa}$ and a holding time of $15 \mathrm{~min}$. The sintering temperature was well below the crystallization temperature of the amorphous alloy $\left(\mathrm{T}_{\mathrm{x}}=653^{\circ} \mathrm{C}\right)$. For comparison, monolithic BMG specimens ( 0 wt $\%$ graphite) were also processed with similar processing conditions. The density of the sintered discs was determined using Archimedes' principle. The phase analysis of the sintered specimens was performed using X-ray diffraction (XRD) system (Philips PW 3710, Almelo, The Netherlands) operating with $\mathrm{Cu} \operatorname{K} \alpha(\lambda=1.54178 \AA)$ radiation. A micro-hardness tester (Buehler, Lake Bluff, IL, USA) was used for measuring hardness by performing indentations at a load of $2.94 \mathrm{~N}$. The dry sliding wear tests were performed on the polished BMG and BMG/graphite composite discs using a ball-on-disc tribometer (Nanovea, Irvin, CA, USA) at the sliding velocity of $0.1 \mathrm{~m} \cdot \mathrm{s}^{-1}$ for a total sliding distance of $1000 \mathrm{~m}$ under normal loads of $10 \mathrm{~N}$ and $20 \mathrm{~N}$. A $6 \mathrm{~mm}$ diameter $\mathrm{Si}_{3} \mathrm{~N}_{4}$ ball was used as a counter body. Weight loss of the samples after the wear tests was recorded for the calculation of the wear rate. The surfaces of the samples before and after the wear tests were observed under a scanning electron microscope (JEOL JSM-6360, Tokyo, Japan) for microstructural analysis.

\section{Results and Discussion}

\subsection{Microstructure of BMG/Graphite Composite}

Figure 1 presents the XRD patterns of SPS sintered BMG and BMG/graphite composites. The BMG samples ( $0 \%$ graphite) exhibited a broad halo peak in the $2 \theta$ range of $41^{\circ}-46^{\circ}$, indicating that the amorphous structure was retained in the compacts sintered at $575{ }^{\circ} \mathrm{C}$. Interestingly, all BMG/graphite composites sintered at $575{ }^{\circ} \mathrm{C}$ showed a halo background peak with superimposed sharp peaks corresponding to the crystalline phase $\mathrm{Fe}_{23}(\mathrm{C}, \mathrm{B})_{6}$. The intensity of crystalline peaks was significantly higher for the BMG/graphite composites with higher graphite content. As the sintering temperature is below the crystallization temperature $\left(\mathrm{T}_{\mathrm{x}}=653{ }^{\circ} \mathrm{C}\right)$, it appears that the addition of graphite alters the local thermal effects, causing crystallization due to partial devitrification of the amorphous alloy or reaction between the constituents of the BMG/graphite composites. The formation of new phases, due to reactions between the constituent phases of the amorphous matrix composites during processing, is widely reported. For example, Siegrist et al. reported formation of $\mathrm{ZrC}$ at the interfaces of graphite particles and Zr-based amorphous matrix in the cast composites [14]. Wang et al. also observed formation of $\mathrm{ZrC}$ in laser clad graphite/Zr-based amorphous alloy composites [18]. The formation of such phases significantly influences the tribological properties of the amorphous matrix composites. The XRD patterns (Figure 1) of the BMG/graphite also showed 
peaks corresponding to the graphite phase, especially at higher graphite content ( $2 \mathrm{wt} \%-4 \mathrm{wt} \%)$. Clearly, the microstructure of the BMG/graphite composites was complex, with the presence of several constituents such as amorphous matrix phase, graphite phase, and crystallization products.

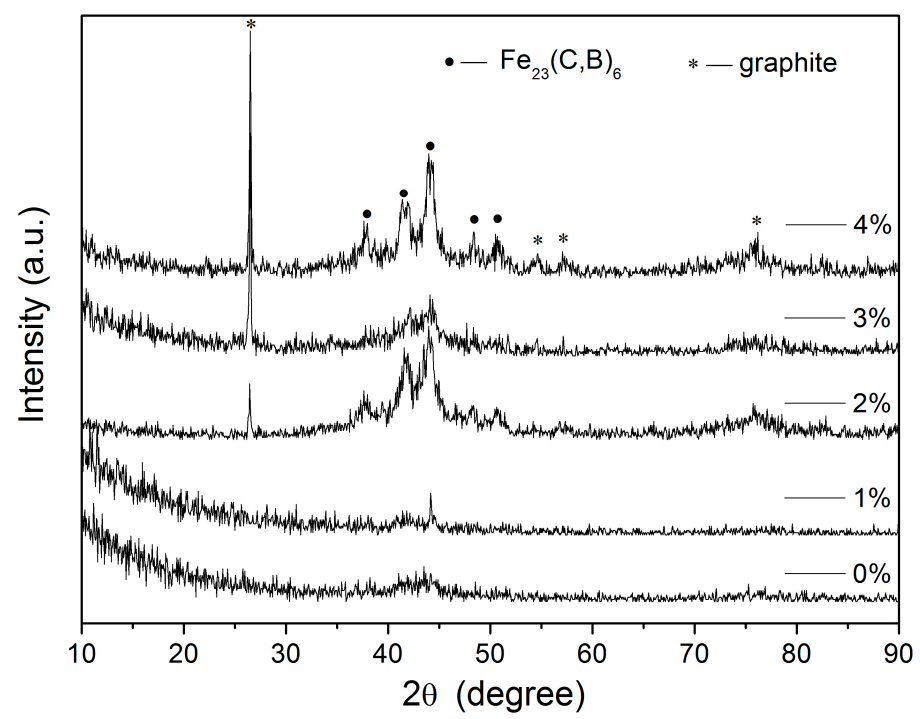

Figure 1. X-ray diffraction patterns of bulk metallic glass (BMG) and BMG/graphite composites (graphite content of $1 \mathrm{wt} \%, 2 \mathrm{wt} \%, 3 \mathrm{wt} \%$ and $4 \mathrm{wt} \%$ ).

The SEM micrographs of the SPS sintered BMG and BMG/graphite composites are presented in Figure 2. All the sintered samples exhibited considerable porosity (gray areas). The BMG samples were relatively denser with distributed porosity. The measured density of the BMG samples was about $7.798 \mathrm{~g} \cdot \mathrm{cm}^{-3}$. In the BMG/graphite composites, well distributed graphite particles (black regions) can be clearly observed. As the addition of graphite is increased, more and more graphite particles (black regions) can be seen in the BMG/graphite composites. A high magnification image of BMG/graphite composite with $4 \mathrm{wt} \%$ graphite shows polygonal amorphous particles welded together with distributed porosity. The graphite particles are trapped in the porosity and between the amorphous particles. The addition of low density reinforcement such as graphite in denser metallic matrices reduces the density of the composites. The densities of BMG/graphite composites with $1 \mathrm{wt} \%, 2 \mathrm{wt} \%, 3 \mathrm{wt} \%$ and $4 \mathrm{wt} \%$ graphite addition were about $7.608 \mathrm{~g} \cdot \mathrm{cm}^{-3}, 7.577 \mathrm{~g} \cdot \mathrm{cm}^{-3}$, $7.277 \mathrm{~g} \cdot \mathrm{cm}^{-3}$ and $7.083 \mathrm{~g} \cdot \mathrm{cm}^{-3}$, respectively.

\subsection{Hardness and Tribology Properties}

The microhardness of the sintered BMG compacts was about $1400 \mathrm{HV}$. The reinforcement of the graphite in the BMG resulted is a slight decrease in hardness. The hardness of the BMG/graphite composites was in the range of 1250-1300 HV. Interestingly, one of the previous studies on laser cladding of graphite/Zr-based amorphous alloy composites showed increasing hardness with the addition of graphite [18]. However, the laser cladding resulted in extensive devitrification of the alloy, forming $\mathrm{Zr}_{3} \mathrm{Al}$ and $(\mathrm{Cu}, \mathrm{Ni})_{10} \mathrm{Zr}_{7}$ phases, and $\mathrm{ZrC}$ carbide at higher graphite content in the composites. It should be noted that the hardness of the composites is significantly influenced by the microstructure and phases of the composites after materials processing, and it is rather difficult to delineate the effect of graphite alone on the hardness. The BMG/graphite composites SPS sintered in this study showed some degree of crystallization. The crystallization products, identified as $\mathrm{Fe}_{23}(\mathrm{C}, \mathrm{B})_{6}$, often increases the hardness of the composites [28]. The reduction in the hardness of the BMG/graphite composites in the present investigation is likely due to the net effect of graphite reinforcement, increased porosity, and crystallization. 


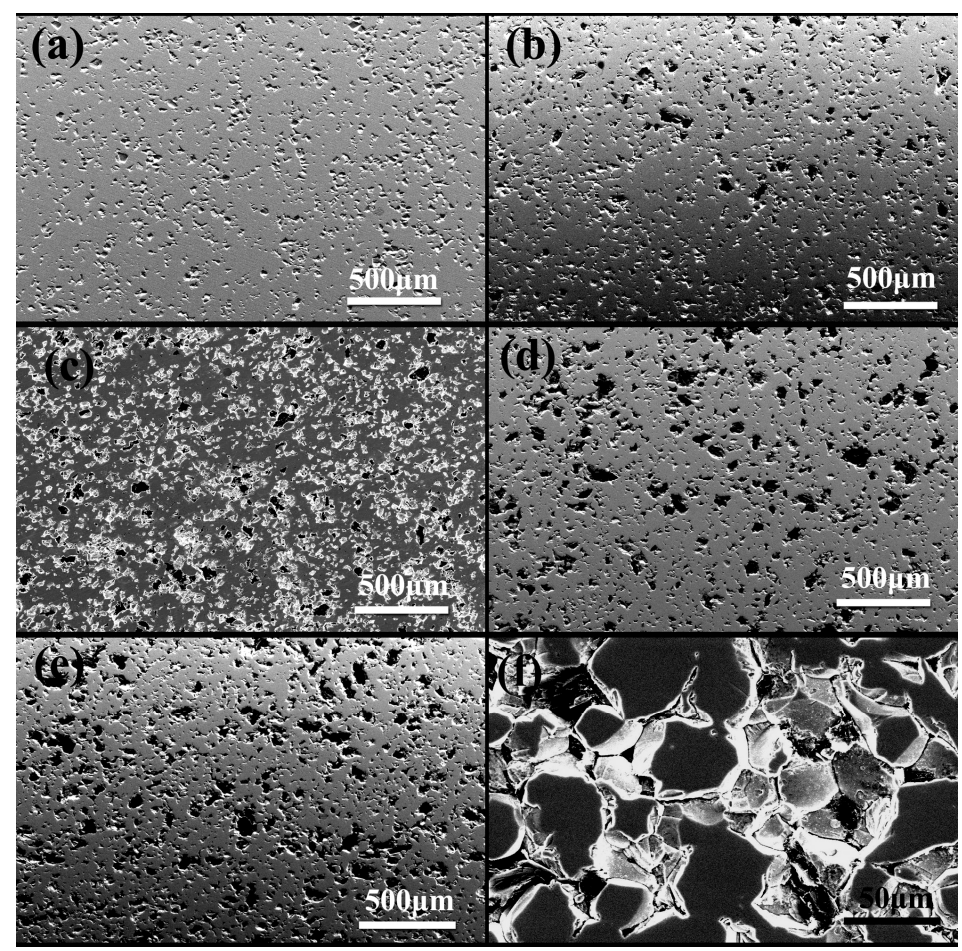

Figure 2. Surface microstructure of: (a) BMG; (b) BMG-1 wt \% graphite; (c) BMG-2 wt \% graphite; (d) BMG-3 wt \% graphite; (e) BMG-4 wt \% graphite; (f) BMG-4 wt \% graphite at high magnification.

Figure 3 shows the wear rate and coefficient of friction (COF) of BMG and BMG/graphite composites at the normal loads of $10 \mathrm{~N}$ and $20 \mathrm{~N}$. The wear rate of BMG ( $0 \%$ graphite) was about $0.089 \times 10^{-3} \mathrm{~mm}^{3} \cdot \mathrm{m}^{-1}$ after $1000 \mathrm{~m}$ sliding distance under a $10 \mathrm{~N}$ applied load (Figure 3a). With the applied load increased to $20 \mathrm{~N}$, the wear rate was increased more than two times to $0.216 \times 10^{-3} \mathrm{~mm}^{3} \cdot \mathrm{m}^{-1}$. While the BMG/graphite composites showed a marked reduction in wear rates at both $10 \mathrm{~N}$ and $20 \mathrm{~N}$ of normal loads, a clear trend of the wear rate decreasing as the graphite content increased was observed for the normal load of $10 \mathrm{~N}$. The wear rate of BMG/graphite composite with $4 \mathrm{wt} \%$ graphite was $0.042 \times 10^{-3} \mathrm{~mm}^{3} \cdot \mathrm{m}^{-1}$ under a $10 \mathrm{~N}$ applied load. The COF of BMG was 0.841 at the load of $10 \mathrm{~N}$ (Figure $3 \mathrm{~b}$ ). When the applied load was increased from $10 \mathrm{~N}$ to $20 \mathrm{~N}$, a slight decrease in the COF was observed. The BMG/graphite composites exhibited a lower COF than BMG at both $10 \mathrm{~N}$ and $20 \mathrm{~N}$ of normal loads. A general trend of a decreasing COF as the graphite content increased was observed for BMG/graphite composites. The COF for BMG/graphite composites with $4 \mathrm{wt} \%$ graphite were 0.668 and 0.587 for $10 \mathrm{~N}$ and $20 \mathrm{~N}$, respectively. Clearly, the reinforcement of graphite in BMG resulted in reduction in both the wear rate and COF. The reduction in the COF, with the addition of graphite in the composite, is attributed to the lubricating effect of graphite solid lubricant. Similar observations have been made for graphite reinforced, Zr-based, bulk amorphous alloys [14,18]. Note that the BMG/graphite composites processed in this study exhibited lower hardness than the BMG compacts. The observations support the arguments that the wear resistance of the BMGs and its composites does not always scale up with the hardness of the material. Figure 4 shows the COF curves for BMG/graphite composites sliding against a $\mathrm{Si}_{3} \mathrm{~N}_{4}$ ball. For all the composites, the COF increases slowly in the early stages of wear (running-in) and reaches an almost stable value (steady state). It is clear that increasing graphite content in BMG/graphite composites extends the running-in process, resulting in an overall lower COF. 

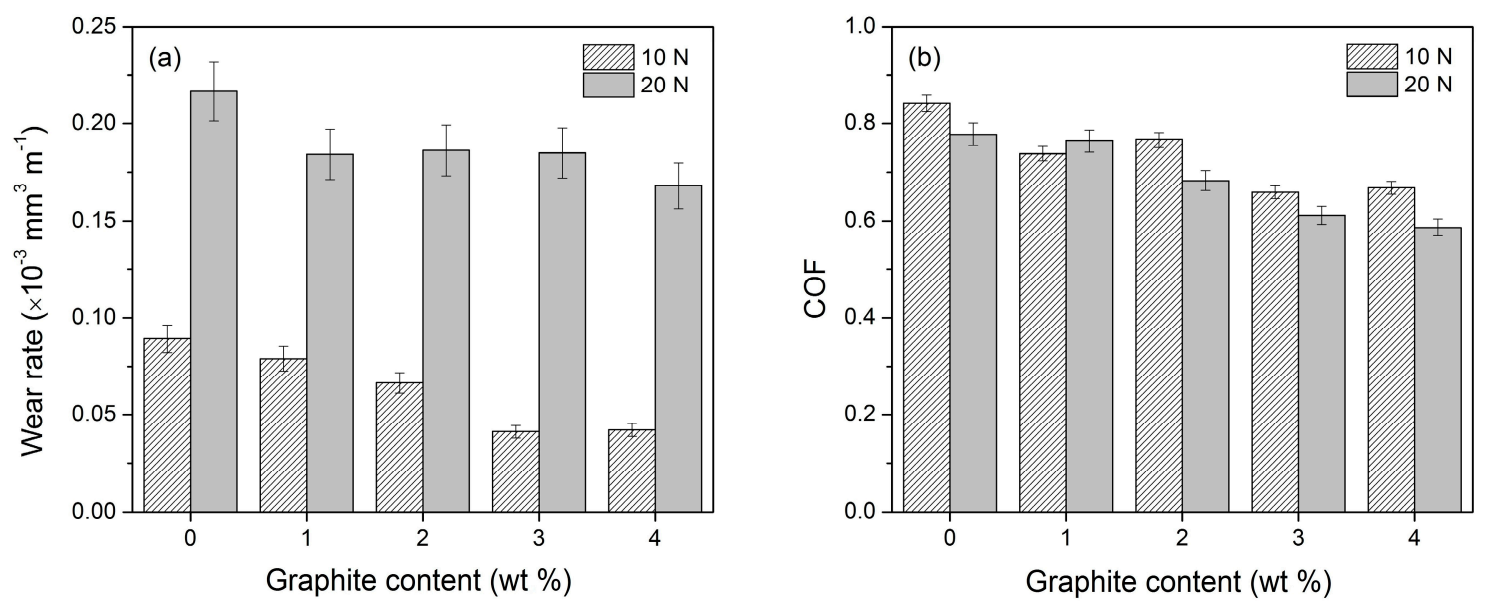

Figure 3. (a) Average wear rate; (b) coefficient of friction (COF) of the BMG and $\mathrm{BMG} /$ graphite composites.

(a)
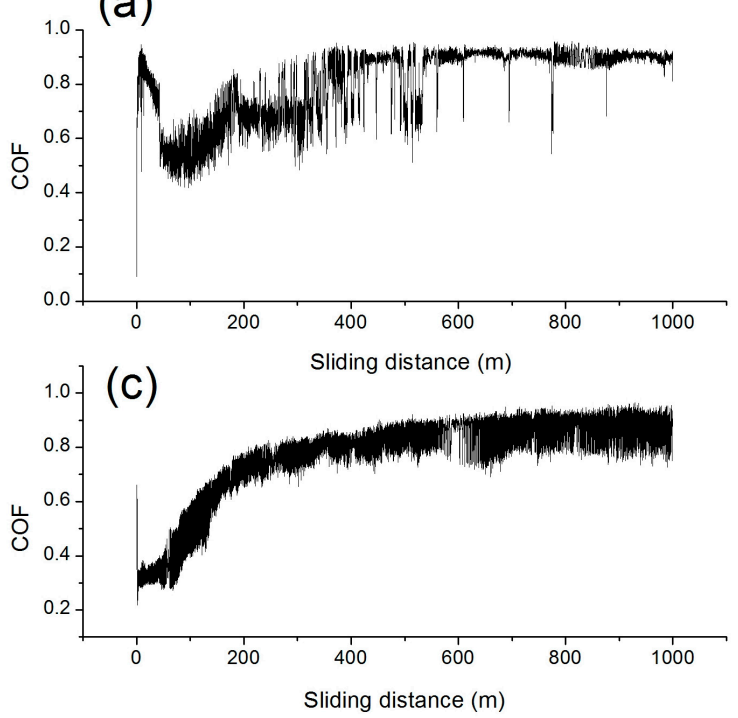

(b)

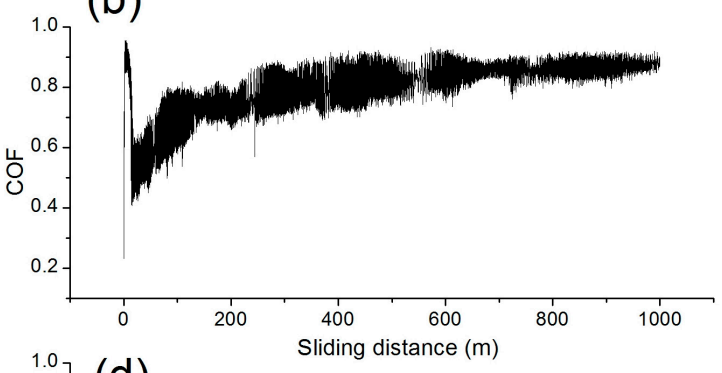

(d)

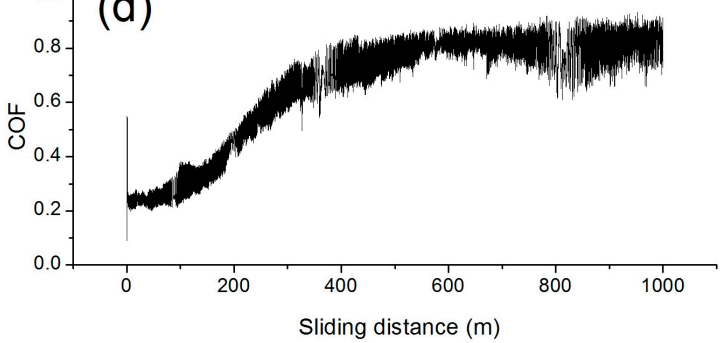

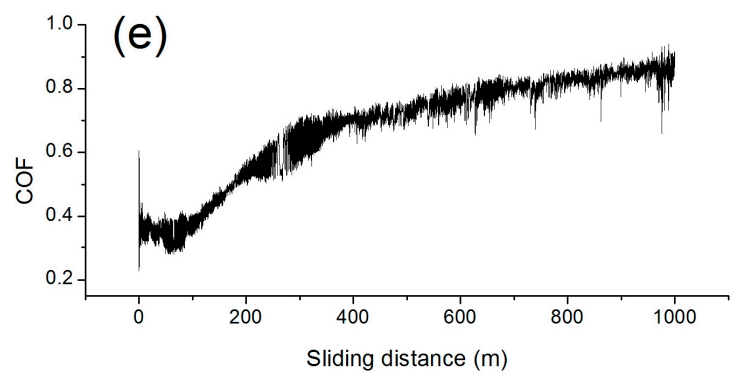

Figure 4. The COF traces for (a) BMG; (b) BMG-1 wt \% graphite; (c) BMG-2 wt \% graphite; (d) BMG-3 wt \% graphite; (e) BMG-4 wt \% graphite composites under a normal load of $20 \mathrm{~N}$.

The SEM micrographs from the worn surfaces of BMG and BMG/graphite composites after sliding wear under the normal load of $20 \mathrm{~N}$ are presented in Figure 5. A very well defined wear track with accumulated debris at the center of the track can be seen for the BMG samples (Figure 5a). The abrasive wear marks, characterized by scratches along the sliding direction, can be at the sides of the wear track. The wear surfaces of BMG/graphite compacts, especially at the graphite content of $1 \mathrm{wt} \%-3 \mathrm{wt} \%$, show localized regions of material loss. It appears that the addition of graphite, along with the 
presence of porosity, weakens the bonding between amorphous alloy particles at localized regions, causing excessive material removal. Also, note that the BMG/graphite composites also showed some degree of crystallization. The crystallization in BMGs often results in embrittlement. The localized loss of material without visible deformation is likely due to microcracking and brittle fracture of the material under sliding wear conditions. Other regions of the BMG/graphite composites are covered with a surface layer. It appears that the graphite particles exposed on the surface, or those pulled out from underneath due to brittle fracture, are smeared on the contact surface, forming a thin lubricating film. The surface layer covers a much larger area and appears to be much thicker in the BMG/graphite composite with $4 \mathrm{wt} \%$ graphite. The formation of surface layers between sliding surfaces has long been known to reduce wear and is also reported for other amorphous alloy compositions [14,18].

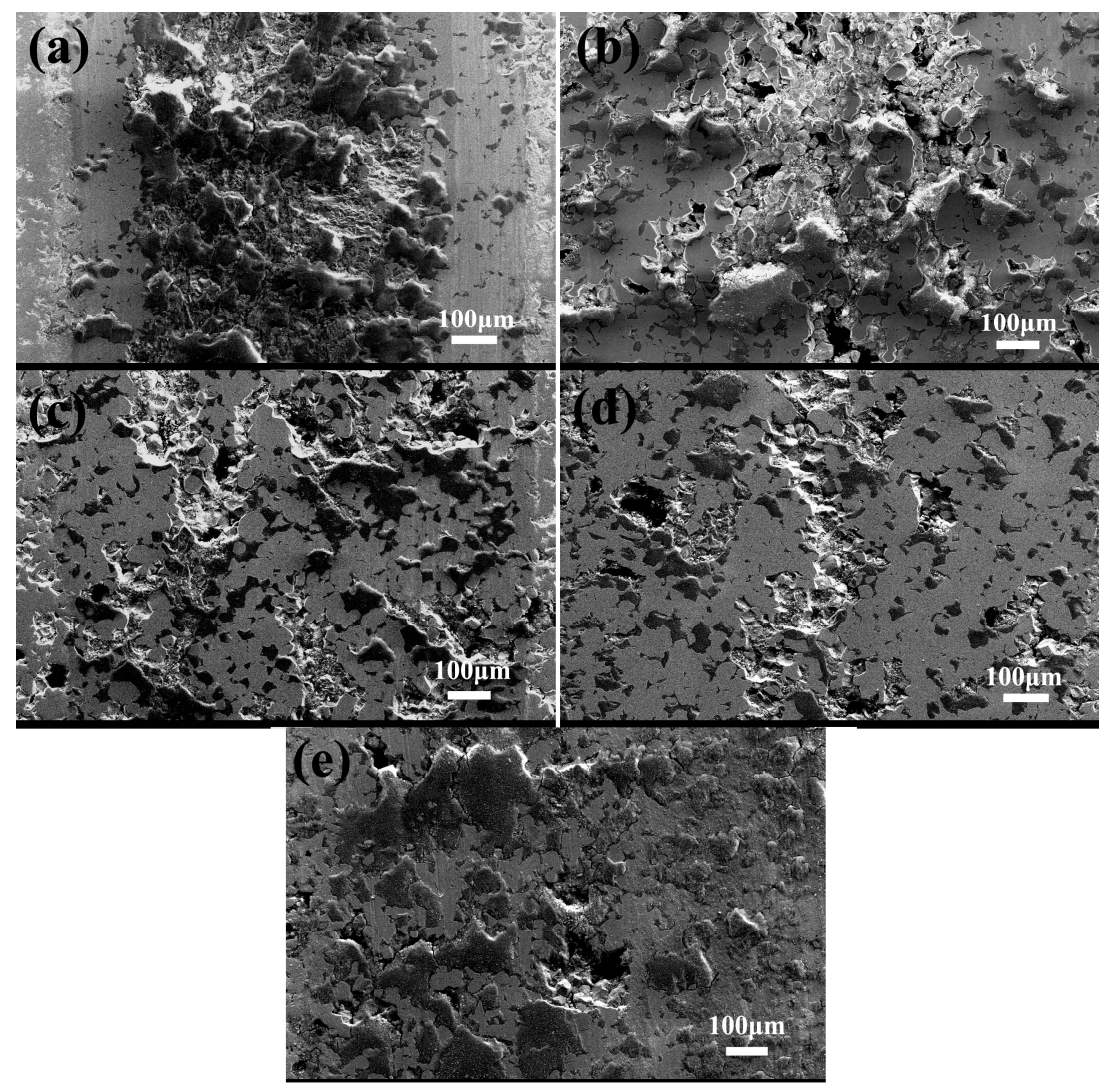

Figure 5. SEM images from wear tracks of (a) BMG; (b) BMG-1 wt \% graphite; (c) BMG-2 wt \% graphite; (d) BMG-3 wt \% graphite; (e) BMG-4 wt \% graphite composites.

\section{Conclusions}

Spark plasma sintering was used to fabricate Fe-based BMG and BMG/graphite composites with a sintering temperature of $575{ }^{\circ} \mathrm{C}$ and a holding time of $15 \mathrm{~min}$. The BMG/graphite composites showed enhanced devitrification with the formation of $\mathrm{Fe}_{23}(\mathrm{C}, \mathrm{B})_{6}$, with an increasing graphite content. Even though the BMG/graphite composites exhibited relatively lower microhardness than the monolithic BMG samples, the composites showed a lower wear rate under dry sliding wear conditions. The observations support the arguments that the wear resistance of the BMG and composites does not always scale up with the hardness. The addition of graphite extended the running-in stage of the friction, resulting in an overall lower coefficient of friction for the composites. The wear surfaces of the BMG/graphite composites showed regions of localized material removal due to microcracking and fracture, as was also the case with the regions covered with a graphite-rich protective film due to smearing of pulled off graphite particles. 
Acknowledgments: S.P.H. would like to acknowledge the financial support from the U.S. National Science Foundation (CMMI-1462602). X.J. would like to thank the financial support provided by the National Natural Science Foundation of China (No. 51475140), the Natural Science Foundation of Jiangsu Province (No. BK20141155), the International S \& T Cooperation Program of Changzhou (CZ20150011), and the Fundamental Research Funds for the Central Universities (2015B19914).

Author Contributions: X.J., S.H.A., and S.P.H. conceived, designed, and performed the experiments; X.J. and S.P.H. analyzed the data; S.P.H and X.J. contributed reagents/materials/analysis tools; X.J., S.H.A., and S.P.H. wrote the paper.

Conflicts of Interest: The authors declare no conflict of interest.

\section{References}

1. Ashby, M.F.; Greer, A.L. Metallic glasses as structural materials. Scripta Mater. 2006, 54, 321-326. [CrossRef]

2. Schroers, J.; Kumar, G.; Hodges, T.M.; Chan, S.; Kyriakides, T.R. Bulk metallic glasses for biomedical applications. JOM 2009, 61, 21-29. [CrossRef]

3. Schroers, J.; Pham, Q.; Desai, A. Thermoplastic forming of bulk metallic glass-A technology for mems and microstructure fabrication. J. Microelectromech. Syst. 2007, 16, 240-247. [CrossRef]

4. Löffler, J.F. Bulk metallic glasses. Intermetallics 2003, 11, 529-540. [CrossRef]

5. Inoue, A.; Shen, B.; Nishiyama, N. Development and applications of late transition metal bulk metallic glasses. In Bulk Metallic Glasses; Miller, M., Liaw, P., Eds.; Springer US: Boston, MA, USA, 2008; pp. 1-25.

6. Singh, A.; Bakshi, S.R.; Agarwal, A.; Harimkar, S.P. Microstructure and tribological behavior of spark plasma sintered iron-based amorphous coatings. Mater. Sci. Eng. A 2010, 527, 5000-5007. [CrossRef]

7. Basu, A.; Samant, A.N.; Harimkar, S.P.; Majumdar, J.D.; Manna, I.; Dahotre, N.B. Laser surface coating of Fe-Cr-Mo-Y-B-C bulk metallic glass composition on AISI 4140 steel. Surf. Coat. Technol. 2008, 202, 2623-2631. [CrossRef]

8. Sahasrabudhe, H.; Bandyopadhyay, A. Laser processing of Fe based bulk amorphous alloy coating on zirconium. Surf. Coat. Technol. 2014, 240, 286-292. [CrossRef]

9. Prakash, B. Abrasive wear behaviour of Fe, Co and Ni based metallic glasses. Wear 2005, 258, $217-224$. [CrossRef]

10. Greer, A.L.; Rutherford, K.L.; Hutchings, I.M. Wear resistance of amorphous alloys and related materials. Int. Mater. Rev. 2002, 47, 87-112. [CrossRef]

11. Hodge, A.M.; Nieh, T.G. Evaluating abrasive wear of amorphous alloys using nanoscratch technique. Intermetallics 2004, 12, 741-748. [CrossRef]

12. Paul, T.; Alavi, S.H.; Biswas, S.; Harimkar, S.P. Microstructure and wear behavior of laser clad multi-layered Fe-based amorphous coatings on steel substrates. Lasers Manuf. Mater. Process. 2015, 2, 231-241. [CrossRef]

13. Singh, A.; Paital, S.R.; Andapally, A.; Dahotre, N.B.; Harimkar, S.P. Densification behavior and wear response of spark plasma sintered iron-based bulk amorphous alloys. Adv. Eng. Mater. 2012, 14, 400-407. [CrossRef]

14. Siegrist, M.E.; Amstad, E.D.; Löffler, J.F. Tribological properties of graphite-and ZrC-reinforced bulk metallic glass composites. Intermetallics 2007, 15, 1228-1236. [CrossRef]

15. Matthews, D.; Ocelik, V.; De Hosson, J.T.M. Tribological and mechanical properties of high power laser surface-treated metallic glasses. Mater. Sci. Eng. A 2007, 471, 155-164. [CrossRef]

16. Harimkar, S.P.; Paital, S.R.; Wang, G.; Liaw, P.K.; Dahotre, N.B. Periodically laser patterned Fe-B-Si amorphous ribbons: Phase evolution and mechanical behavior. Adv. Eng. Mater. 2011, 13, 955-960. [CrossRef]

17. Ji, X.; Alavi, S.H.; Harimkar, S.P. High-temperature sliding wear behavior of Zr-based bulk amorphous alloys. JOM 2015, 67, 1578-1584. [CrossRef]

18. Wang, Y.; Li, G.; Shi, Z.; Liu, M.; Zhang, X.; Liu, Y. Effects of graphite addition on the microstructure and properties of laser cladding $\mathrm{Zr}-\mathrm{Al}-\mathrm{Ni}-\mathrm{Cu}$ amorphous coatings. J. Alloys Compd. 2014, 610, 713-717. [CrossRef]

19. Roy, D.; Singh, S.S.; Basu, B.; Lojkowski, W.; Mitra, R.; Manna, I. Studies on wear behavior of nano-intermetallic reinforced al-base amorphous/nanocrystalline matrix in situ composite. Wear 2009, 266, 1113-1118. [CrossRef]

20. Gloriant, T. Microhardness and abrasive wear resistance of metallic glasses and nanostructured composite materials. J. Non-Cryst. Solids 2003, 316, 96-103. [CrossRef] 
21. Huang, K.J.; Yan, L.; Wang, C.S.; Xie, C.S.; Zhou, C.R. Wear and corrosion properties of laser cladded $\mathrm{Cu}_{47} \mathrm{Ti}_{34} \mathrm{Zr}_{11} \mathrm{Ni}_{8} / \mathrm{SiC}$ amorphous composite coatings on AZ91D magnesium alloy. Trans. Nonferrous Met. Soc. China 2010, 20, 1351-1355. [CrossRef]

22. Yue, T.M.; $\mathrm{Su}$, Y.P. Laser cladding of sic reinforced $\mathrm{Zr}_{65} \mathrm{Al}_{7.5} \mathrm{Ni}_{10} \mathrm{Cu}_{17.5}$ amorphous coating on magnesium substrate. Appl. Surf. Sci. 2008, 255, 1692-1698. [CrossRef]

23. Lu, Z.P.; Liu, C.T.; Thompson, J.R.; Porter, W.D. Structural amorphous steels. Phys. Rev. Lett. 2004, 92, 245503. [CrossRef] [PubMed]

24. Ponnambalam, V.; Poon, S.J.; Shiflet, G.J. Fe-based bulk metallic glasses with diameter thickness larger than one centimeter. J. Mater. Res. 2004, 19, 1320-1323. [CrossRef]

25. Graeve, O.A.; Kanakala, R.; Kaufman, L.; Sinha, K.; Wang, E.; Pearson, B.; Rojas-George, G.; Farmer, J.C. Spark plasma sintering of Fe-based structural amorphous metals (SAM) with $\mathrm{Y}_{2} \mathrm{O}_{3}$ nanoparticle additions. Mater. Lett. 2008, 62, 2988-2991. [CrossRef]

26. Harimkar, S.P.; Paital, S.R.; Singh, A.; Aalund, R.; Dahotre, N.B. Microstructure and properties of spark plasma sintered Fe-Cr-Mo-Y-B-C bulk metallic glass. J. Non-Cryst. Solids 2009, 355, 2179-2182. [CrossRef]

27. Singh, A.; Harimkar, S.P. Spark plasma sintering of in situ and ex situ iron-based amorphous matrix composites. J. Alloys Compd. 2010, 497, 121-126. [CrossRef]

28. Singh, A.K.; Alavi, S.H.; Paital, S.R.; Dahotre, N.B.; Harimkar, S.P. Structural relaxation and nanocrystallization-induced laser surface hardening of Fe-based bulk amorphous alloys. JOM 2014, 66, 1080-1087. [CrossRef]

(C) 2016 by the authors; licensee MDPI, Basel, Switzerland. This article is an open access article distributed under the terms and conditions of the Creative Commons Attribution (CC-BY) license (http://creativecommons.org/licenses/by/4.0/). 